\title{
Continuous flow liquid membrane extraction: a novel automatic trace-enrichment technique based on continuous flow liquid-liquid extraction combined with supported liquid membrane
}

\author{
Jing-Fu Liu ${ }^{a}$, Jing-Bo Chao ${ }^{b}$, Gui-Bin Jiang ${ }^{a}$ * \\ ${ }^{a}$ Research Center for Eco-Environmental Sciences, Chinese Academy of Sciences, P.O. Box 2871, Beijing 100085, China \\ ${ }^{\mathrm{b}}$ Department of Chemistry, Beijing University of Science and Technology, Beijing 100083, China
}

Received 25 July 2001; accepted 26 November 2001

\begin{abstract}
Combining the continuous flow liquid-liquid extraction (CFLLE) and supported liquid membrane (SLM) extraction, a novel aqueous-aqueous extraction technique that we termed continuous flow liquid membrane extraction (CFLME) is developed for trace-enrichment. The analyte was firstly extracted into the organic phase in the CFLLE step, then transported onto the organic liquid membrane that formed on the surface of the micro porous membrane of the SLM equipment. Finally, it passed through the liquid membrane and was trapped by the acceptor. Aspects related to CFLME were studied by using dichloromethane as liquid membrane, and sulfonylurea herbicides as model compounds. An enrichment factor of over 1000 was obtained when $10 \mu \mathrm{g}^{-1}$ of MSM was enriched for $120 \mathrm{~min}$ by this technique. The drawbacks of only a few organic solvents can be selected as liquid membrane with a limited lifetime in SLM operation was overcome. In this CFLME method, almost all solvents that used in the conventional liquid-liquid extraction (LLE) can be adopted and the lifetime of liquid membrane is no longer a problem. () 2002 Elsevier Science B.V. All rights reserved.
\end{abstract}

Keywords: Trace-enrichment; Continuous flow liquid membrane extraction; Continuous flow liquid-liquid extraction; Supported liquid membrane (SLM); Sulfonylurea herbicides

\section{Introduction}

Sample pretreatment now is still the weakest link and the time-determining step in the whole analytical procedure and the primary sources of errors [1]. The increasing need for determination of numerous analytes at lower and lower levels and in more and more complex matrixes makes the sample pretreatment, especially trace-enrichment, to be an indispensable step in many analytical procedures.

\footnotetext{
* Corresponding author. Fax: +86-10-62923563.

E-mail address: gbjiang@mail.recees.ac.cn (G.-B. Jiang).
}

Trace-enrichment can be performed by liquid-liquid extraction (LLE) or solid phase extraction (SPE). Although, SPE is a relatively more recent and popular technique, LLE is still one of the most versatile techniques for enrichment because of its advantages such as requirement for simple and non-expensive equipment, high capacity for interfering compounds, high potential for chemically tuning the separation by incorporating different specific reagents and simplicity for performing. The main drawbacks of LLE are high consumption of solvents and easy formation of emulsions.

Many efforts have been made to overcome these inherent drawbacks of LLE. Among them, the most 
successful techniques are probably the continuous flow liquid-liquid extraction (CFLLE) and supported liquid membrane (SLM) extraction using flow system [2-4].

CFLLE consists of the continuous flow analysis based LLE (CFA-LLE) [5,6] and the flow injection analysis based LLE (FIA-LLE) [7,8]. Generally, the enrichment factors that can be achieved are limited to about 15-20 times [9,10].

CFA-LLE and FIA-LLE are very similar except that samples were injected into the system with an injection valve in FIA-LLE. Typically, these two techniques involve three steps: (i) segmentation of the two immiscible organic and aqueous phases; (ii) distribution of sample components between the two phases and (iii) separation of one or both phases for determination.

The extraction processes within FIA-LLE have been extensively studied $[11,12]$ and it was found that the organic film, formed on the wall of a hydrophobic tubing such as teflon and the successive segments of organic solvent and aqueous sample plays a very important role. To a great extent, the extraction takes place at the interface of this film. Rapid extraction occurs between the two phases as a result of the high surface area:volume ratio and the toroidal mixing within each segment.

Making use of the differential flow velocities in two-phase segmented flow due to the film-forming on teflon tubing [13], Lucy and Varkey [14] developed a system for pre-concentration of $o$-nitrophenol with an enrichment factor in excess of 50-fold and a throughput of $30 \mathrm{~h}^{-1}$. Later, Luo et al. [15] described a novel solvent extraction-flow/sequential injection analysis system based on the film-forming characteristics of an organic phase on a teflon tube wall. The system can be operated at sample frequencies of $10 \mathrm{~h}^{-1}$ with an enrichment factor of 150 .

SLM extraction, an alternative approach to trace-enrichment, was firstly applied to analytical purpose by Audusson in the mid 1980s [3]. It is based on a three-phase system with an organic phase sandwiched between two aqueous phases (the donor and the acceptor) in a flow system, the organic phase is immobilized in a porous hydrophobic membrane. The principles and applications of SLM extraction methods have been discussed and reviewed by Jönsson and Mathiasson [2,16-18].
SLM extraction has been applied to a variety of sample preparation and enrichment in environmental and biological analysis [16], as it has many advantages such as high selectivity, high degree of concentration enrichment, very low consumption of organic solvents and convenient to be on-line coupled with chromatographic and spectroscopic instruments $[3,4,18]$. Traces of sulfonylurea $[19,20]$ and triazine herbicides [21-23], phenoxy acids [24,25], chlorophenols [26], aniline derivates [27] and metal ions [28,29] have been enriched from water samples by SLM. SLM extraction was also found suitable for enrichment of basic drugs in human plasma [30,31]. The reported enrichment factors of SLM were typically in the range of 10-200, except in the case of metal elements $(\mathrm{Cu}$, $\mathrm{Pb}$ and $\mathrm{Cd}$ ) were preconcentrated with hollow fiber based SLM system in which high enrichment factors in the range of 100-3000 can be obtained [29].

The drawbacks of SLM are its limited lifetime of the liquid membrane, especially when polar organic solvents were used and the relatively low enrichment rate that results in long enrichment time when very large enrichment factors are needed.

The objective of this work was to develop an automatic sample pretreatment system with high enrichment rate and long-term stability. To achieve this goal, an aqueous-aqueous extraction system developed by combination of CFLLE and SLM, which we have termed continuous flow liquid membrane extraction (CFLME), is proposed. It involved the following steps: (i) transfer the analyte into the organic phase in the CFLLE step; (ii) the organic phase was transported to the SLM equipment and formed an organic film on the surface of the membrane and (iii) the analyte passes through the liquid membrane, formed in a porous hydrophobic membrane, and finally trapped by the acceptor.

Parameters that influence the performance of this system were investigated by using sulfonylurea herbicides as model compounds.

\section{Experimental}

\subsection{Apparatus}

A schematic diagram of the flow system is shown in Fig. 1. The two peristaltic pumps (P1 and P2) of the FIA 5020 analyzer (Tecator, Sweden) were employed 


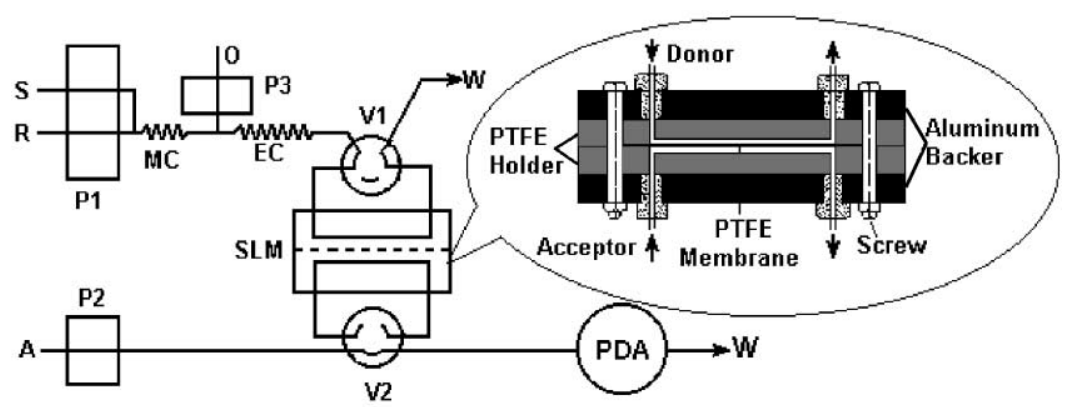

(a)

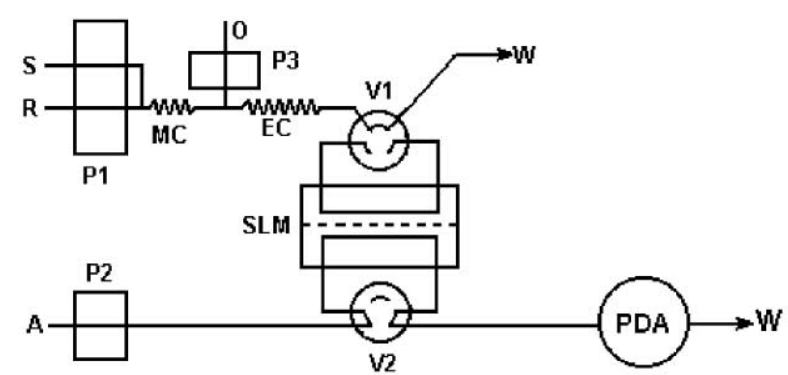

(b)

Fig. 1. Schematic diagram of the proposed CFLME system: (a) enrichment and (b)detection; S, sample solution; R, 0.5 M sulfuric acid; $\mathrm{O}$, organic solvent; A, acceptor; W, waste; P1, P2, peristaltic pumps; P3, piston pump; MC, mixing coil; EC, extraction coil; V1, V2, 6-port valves; SLM, SLM device; PDA, detector, $240 \mathrm{~nm}$.

to deliver aqueous solutions. Organic solvents were pumped with a piston pump (P3) of the FIA 3000 flow injection analyzer (SNK, Japan). The 6-port vale (V2) equipped in the FIA 5020 analyzer was used to switch the acceptor to entrance into the acceptor channel of the SLM device, while another 6-port valve (V1) was adopted to manually control the entrance of the mixture of sample solution (S), reagent and organic solvent, into the donor of the SLM device. The mixing coil (MC) and extraction coil (EC) were made of $0.5 \mathrm{~mm}$ i.d. polytetrafluoroethylene (PTFE) tubing and T-shaped three-way connectors made from PTFE were used to mix solutions or solvents.

Fig. 1(a) shows the cutaway view of the custom-made SLM device, which consisted of PTFE holder, PTFE membrane and aluminum backer. The PTFE holder was machined from two blocks of teflon by cutting two grooves on the opposite faces of the two blocks. The grooves have identical dimensions of $0.5 \mathrm{~mm}$ depth, $2 \mathrm{~mm}$ width and $50 \mathrm{~mm}$ length. The membrane was clamped tightly and evenly between the planar surfaces of the blocks by six screws. Thus, two channels (the acceptor channel and the donor channel) with the same volume of $50 \mu$ l were obtained. To make the device more rigid, each PTFE block were backed by an aluminum block.

The porous membranes used as support of the immobilized organic liquid are listed in Table 1 with some specifications reported by the manufacturer.

An SPD-M10Avp diode array detector (Shimadzu, Japan) setting at $240 \mathrm{~nm}$ wavelength was used as a detector. Data acquisition and process were accomplished with a Class-VP workstation (Shimadzu), which was connected with the detector with an SCL-10Avp system controller (Shimadzu).

\subsection{Chemicals}

Five kinds of sulfonylurea herbicides studied in this study were obtained from Tianjin Pesticides Factory (Tianjin, China). They were: metsulfuron methyl (MSM, 98.5\%), bensulfuron methyl (BSM, 97.7\%), 
Table 1

Parameters of the investigated porous membranes

\begin{tabular}{llllll}
\hline Membrane & Material & Backing material & $\begin{array}{l}\text { Thickness of } \\
\text { membrane }(\mu \mathrm{m})\end{array}$ & $\begin{array}{l}\text { Average pore } \\
\text { size }(\mu \mathrm{m})\end{array}$ \\
\hline Fluoropore FGLP & PTFE & Polyethene & 60 & 0.2 & 0.7 \\
BSF-II-030 $^{\mathrm{b}}$ & PTFE & - & 60 & 0.3 & 0.57 \\
BSF-II-050 $^{\mathrm{b}}$ & PTFE & - & 80 & 0.5 & 0.60 \\
BSF-II-100 $^{\mathrm{b}}$ & PTFE & - & 80 & 1.0 & 0.65 \\
Nylon $^{\mathrm{c}}$ & Nylon & - & & 0.45 &
\end{tabular}

${ }^{\text {a }}$ Millipore Corp., Bedford, MA.

${ }^{\mathrm{b}}$ Beijing Plastic Research Institute, Beijing, China.

${ }^{c}$ Bio-Rad Lab. Inc.

tribenuron methyl (TBM, 90.5\%), sulfometuron methyl (SMM, 74.5\%) and DPX-A 7881 (DPX-A, $90 \%$ ). Individual standard stock solutions of sulfonylurea herbicides were prepared by dissolving $25 \mathrm{mg}$ of standard in $50 \mathrm{ml}$ of acetonitrile. All the standard stock solutions were stored at $4{ }^{\circ} \mathrm{C}$. Working solutions were obtained daily by appropriately diluting the stock solutions with water.

All other chemicals were purchased from Beijing Chemicals Corporation and were analytical grade or better. De-ionized water was used throughout.

\subsection{Procedure}

Install the whole system as shown in Fig. 1. The teflon face was exposed to the donor phase when the Fluoropore FGLP membrane was used. All new membranes were used as it was purchased without pretreatment. The organic phase was automatically loaded onto the support in situ when the segment of aqueous phase and organic phase passed through the donor channel. When a new organic phase was studied, the old organic phase already existing on the membrane was removed by successive forcing $2 \mathrm{ml}$ of acetone and $20 \mathrm{ml}$ of water through both the donor and the acceptor channels of the SLM device with a syringe.

The operation of the system is best described with reference to Fig. 1 and Table 2. S and diluted sulfuric acid $(\mathrm{R})$ are introduced into the system by a peristaltic pump (P1), these two solutions mixed in a mixing coil (MC) and were segmented by organic solvent (O) delivered by the piston pump (P3). Analytes were extracted into the organic phase in the extraction coil (EC).

When the samples were enriched, the manifold was set at the "enrich position" as shown in Fig. 1(a). The segments of acidified sample and organic phase were introduced into the donor side of the SLM by switching V1 at sampling position; while the acceptor (A) stream, delivered by a peristaltic pump (P2), is stagnant in the acceptor channel of SLM by switching V2 at the bypass position. Therefore, the organic phase formed an organic film on the surface of the PTFE membrane in the SLM device and the analyte passes through the liquid membrane, formed in a porous hydrophobic membrane and finally trapped by the acceptor.

After a certain period of time (typically 10 or $20 \mathrm{~min}$ ), the manifold was changed to the "detection

Table 2

Operational sequence of the proposed CFLME system

\begin{tabular}{lll}
\hline & Step 1 as shown in Fig. 1(a) & Step 2 as shown in Fig. 1(b) \\
\hline Time (min) & $0-20$ & $21-22$ \\
Function & Enrichment & Detection \\
Injector position & $\mathrm{V} 1$ (sampling); V2 (bypass) & $\mathrm{V} 1$ (bypass); V2 (injection) \\
$\begin{array}{l}\text { Pump active and flow rate } \\
\text { in parenthesis }\left(\mathrm{ml} \mathrm{min}^{-1}\right)\end{array}$ & $\mathrm{P} 1$ : on, sample (2.0), 0.5 $\mathrm{M} \mathrm{H}_{2} \mathrm{SO}_{4}(0.4) ;$ & $\mathrm{P} 1$ : on, sample $(2.0), 0.5 \mathrm{M} \mathrm{H} \mathrm{SO}_{4}(0.4) ;$ \\
& $\mathrm{P}$ 3: on, dichloromethane $(0.05) ; \mathrm{P} 2:$ off & $\mathrm{P}$ : on, dichloromethane $(0.05) ; \mathrm{P} 2:$ on, pH \\
& & $12.0 \mathrm{Na}_{2} \mathrm{HPO}_{4}$ buffer $(0.8)$ \\
\hline
\end{tabular}


position" as shown in Fig. 1(b). At this step, V1 was switched to bypass position and V2 is switched to the injection position to introduce the analyte that has been enriched in the acceptor channel of the SLM to the detector (PDA) and the peak height was determined.

All the solutions were degassed by ultrasonic for $30 \mathrm{~min}$ before use to prevent the formation of the air bubbles in the flow system.

\subsection{Quantification}

Peak height difference of the sample and blank solution, containing corresponding concentration of acetonitrile were used for quantification. Enrichment factor $\left(E_{\mathrm{e}}\right)$ was determined by

$E_{\mathrm{e}}=\left(H_{\mathrm{e}} / C_{\mathrm{e}}\right) / H_{\mathrm{i}}$

Here, $H_{\mathrm{e}}$ is the peak height determined by enriching an analyte with initial concentration of $C_{\mathrm{e}}\left(\mathrm{mg}^{-1}\right)$. $H_{\mathrm{i}}$ is the peak height obtained by direct injection of a $1 \mathrm{mg}^{-1} \mathrm{~S}$ prepared in acceptor. Direct injection was conducted by replacing the SLM unit with a sampling loop of $50 \mu$ l, the same volume of the acceptor channel of the SLM device, while keeping the other conditions the same as in the enrichment process.

\section{Results and discussion}

\subsection{Influence of the CFLLE related parameters}

It is well known that the inner diameter and length of EC, the flow rates of sample, reagent and organic solvent, and the ratio of aqueous:organic phase influence significantly the extraction efficiency of a CFLLE system. In this study, optimizations of these parameters were conducted by 20 min enrichment of a S contains $50 \mu \mathrm{gl}^{-1} \mathrm{MSM}$. A solution of $0.32 \mathrm{M}$ $\mathrm{H}_{2} \mathrm{SO}_{4}$ was used to acidify the donor and $12 \mathrm{gl}^{-1}$ $\mathrm{Na}_{2} \mathrm{HPO}_{4} \cdot 12 \mathrm{H}_{2} \mathrm{O}(\mathrm{pH} 9.0)$ was used as acceptor.

Experiments show that the MC did not affect the peak height in the range of $30-100 \mathrm{~cm}$, so a $30 \mathrm{~cm}$ long MC was thus used throughout.

The EC length has significant influence on the peak height. It is reported $[11,12,32]$ that small tubing diameter is helpful for extraction. Therefore, $0.5 \mathrm{~mm}$ i.d. PTFE coil was adopted without optimization, while the coil length was optimized in the range of $60-360 \mathrm{~cm}$. As shown in Fig. 2(a), peak heights increased with the increasing of coil length upto $300 \mathrm{~cm}$, then it decreased gradually. An EC of $300 \mathrm{~cm}$ long was adopted as optimum.

To decrease the dilution factor of sample in the flow system, the flow rate of sulfuric acid should be decreased as low as possible. In this study, $0.4 \mathrm{ml} \mathrm{min}^{-1}$, the lowest flow rate can be obtained, of sulfuric acid was used throughout. The flow rate of acceptor, which does not affect the extraction efficiency, was $0.8 \mathrm{ml} \mathrm{min}^{-1}$.

Keeping the sample flow rate at $1.2 \mathrm{ml} \mathrm{min}^{-1}$, the flow rate of organic phase, dichloromethane, was optimized in the range of $0.05-0.20 \mathrm{ml} \mathrm{min}^{-1}$ and results are shown in Fig. 2(b). Fig. 2(b) indicates that the peak height decreased with the increasing of dichloromethane flow rate as expected, the peak height at $0.20 \mathrm{ml} \mathrm{min}^{-1}$ was only one half of that at $0.05 \mathrm{ml} \mathrm{min}{ }^{-1}$. Though it might be helpful for getting higher peak height, lower flow rate than $0.05 \mathrm{ml} \mathrm{min}^{-1}$ of dichloromethane was not studied as this is the lowest flow rate the instrument can provided. Therefore, $0.05 \mathrm{ml} \mathrm{min}^{-1}$ was used in the following studies.

Keeping the flow rate of $\mathrm{H}_{2} \mathrm{SO}_{4}$ at $0.4 \mathrm{ml} \mathrm{min}^{-1}$ and the concentration of $\mathrm{H}_{2} \mathrm{SO}_{4}$ at $0.08 \mathrm{M}$ after mixing with different flow rates of $\mathrm{S}$, by using appropriate concentration of $\mathrm{H}_{2} \mathrm{SO}_{4}$, the influence of sample flow rate was investigated from 0.4 to $2.8 \mathrm{ml} \mathrm{min}^{-1}$. Results shown in Fig. 2(c) demonstrated that peak height increased with the increase of sample flow rate. Though the highest peak height was obtained at $2.8,2.0 \mathrm{ml} \mathrm{min}-1$ sample flow rate was adopted as the whole flow system is more stable at this flow rate.

\subsection{Influence of the SLM related parameters}

\subsubsection{Support matrix for the liquid membrane}

Using dichloromethane as liquid membrane, five kinds of porous membranes listed in Table 1 were tested as support for the liquid membrane. Five solutions contain $50 \mu \mathrm{g} 1^{-1}$ of individual sulfonylurea herbicides were enriched, respectively with the above optimized flow rates, and an enrichment time of 20 min. A solution of $12.0 \mathrm{gl}^{-1} \mathrm{Na}_{2} \mathrm{HPO}_{4} \cdot 12 \mathrm{H}_{2} \mathrm{O}$ (pH 9.0) was used as acceptor and sulfuric acid of $0.32 \mathrm{M}$ was introduced to acidify the $\mathrm{S}$. 

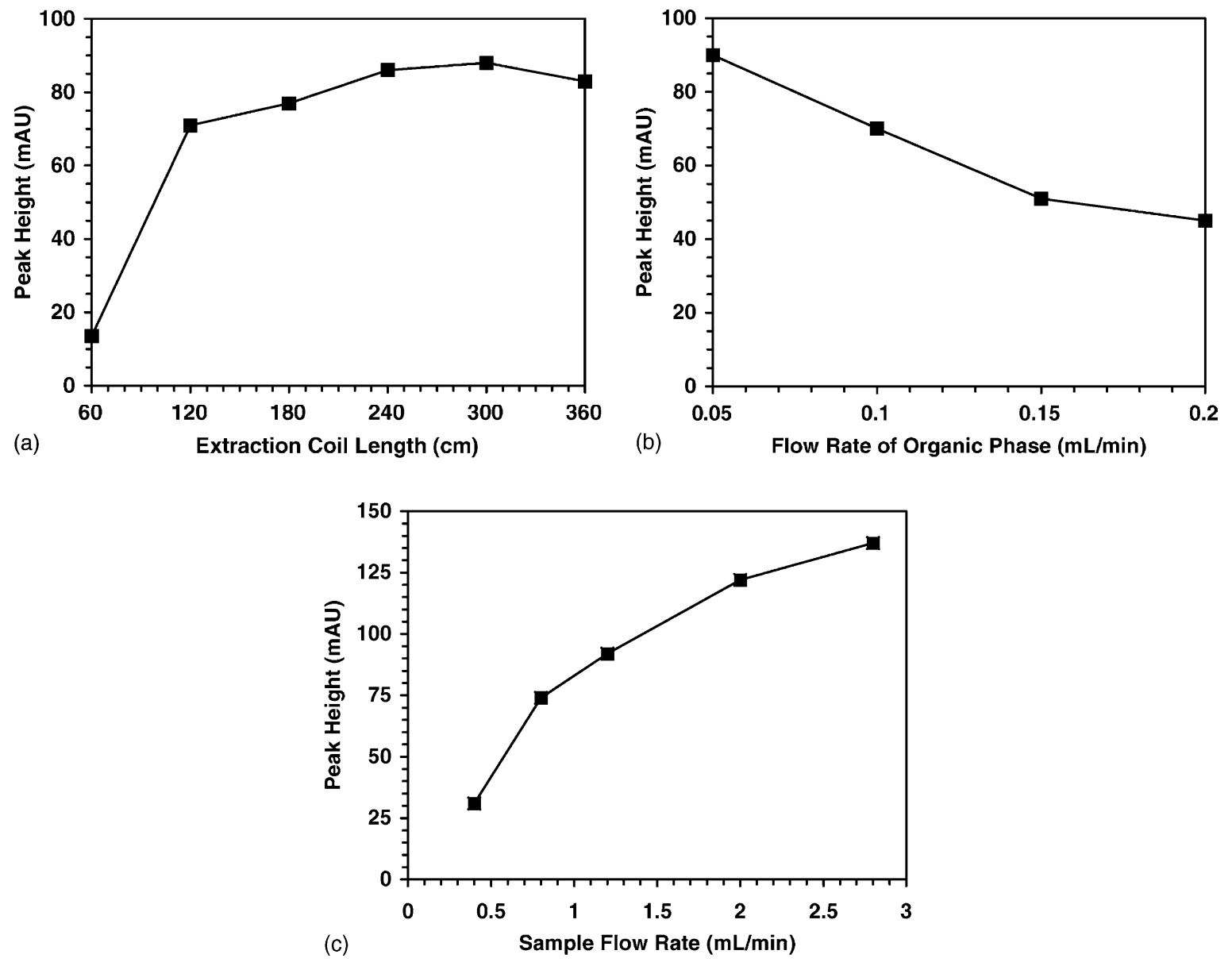

Fig. 2. Effect of flow parameters on the peak heights of $50 \mu \mathrm{gl}^{-1} \mathrm{MSM}$ with 20 min enrichment. Acceptor: $12.0 \mathrm{~g} \mathrm{l}^{-1} \mathrm{Na}_{2} \mathrm{HPO}_{4} \cdot 12 \mathrm{H}_{2} \mathrm{O}$; organic solvent: dichloromethane; $\mathrm{H}_{2} \mathrm{SO}_{4}, 0.32 \mathrm{M}$ at $0.4 \mathrm{ml} \mathrm{min}^{-1}$ flow rate. (a) Effect of extraction coil length; (b) effect of dichloromethane flow rate and (c) effect of sample flow rate.

Results shown in Table 3 indicate clearly that the thinnest membrane, the Fluoropore FG PTFE membrane, gave the highest enrichment factor. Table 3 also indicates that the pore size did not

Table 3

Influence of support matrix for the liquid membrane

\begin{tabular}{llcccc}
\hline Support matrix & \multicolumn{5}{l}{ Enrichment factor, $E_{\mathrm{e}}$} \\
\cline { 2 - 6 } & MSM & BSM & TBM & SMM & DPX-A \\
\hline Fluoropore FGLP & 93 & 88 & 126 & 35 & 275 \\
BSF-II-030 & 48 & 8.0 & 13 & 2.6 & 8.3 \\
BSF-II-050 & 20 & 4.7 & 5.8 & 16 & 75 \\
BSF-II-100 & 20 & 4.7 & 8.0 & 18 & 83 \\
Nylon & 0 & 0 & 0 & 0 & 0 \\
\hline
\end{tabular}

influence the enrich factor significantly in the range of $0.3-1 \mu \mathrm{m}$.

No enrichment effect was observed when nylon membrane was used. The reason is not clear, probably it is because nylon is more hydrophilic than the PTFE, and the organic solvent did not enter the pores of the nylon membrane. Another possibility is that the nylon membrane swelled when contacted with the organic solvents that resulted in the clog of the pores.

Experiments show that when the Fluoropore FGLP membrane was used, the extraction efficiency with teflon face exposed to the donor phase is about 1.3 times of that with the teflon face exposed to the acceptor phase. 
Table 4

Influence of solvent as liquid membrane

\begin{tabular}{lccccc}
\hline Solvent & \multicolumn{5}{l}{ Enrichment factor, $E_{\mathrm{e}}$} \\
\cline { 2 - 6 } & MSM & BSM & TBM & SMM & DPX-A \\
\hline Dichloromethane & 196 & 72 & 50 & 77 & 450 \\
Chloroform & 121 & 16 & 11 & 41 & 241 \\
Tetrachloromethane & 20 & 59 & 25 & 20 & 83 \\
Xylene & 43 & 41 & 10 & 26 & 83 \\
$n$-Hexanol & 15 & 28 & 15 & 15 & 50 \\
$n$-Octanol & 15 & 14 & 7.6 & 5.1 & 17 \\
\hline
\end{tabular}

\subsubsection{Solvent used as the liquid membrane}

In this proposed CFLME system, almost all kinds of organic solvents used in LLE can be used. As the studied analytes are all relatively polar compounds, polar solvents should be beneficial for high enrichment factor according to the rule of likes dissolve in likes. With the same enrichment conditions as used in the selection of support matrix for the liquid membrane (4.2.1), six kinds of relatively polar solvents were tested in this study and the results are shown in Table 4, which indicates that the largest $E_{\mathrm{e}}$ were obtained when dichloromethane was used. Though it is harmful for environment, dichloromethane was adopted in the following studies considering the amount used is very low $\left(3 \mathrm{ml} \mathrm{h}^{-1}\right)$ and the procedure is conducted in a closed system.

\subsubsection{Sulfuric acid concentration in the donor stream}

The compounds studied in this paper are all weak acids, which should be protonized before extraction into organic phase. Sulfuric acid was adopted to acidify the $\mathrm{S}$, and its concentration was optimized by introducing different concentration of sulfuric acid into the donor stream while keeping the flow rate at $0.4 \mathrm{ml} \mathrm{min}-1$. The experimental results are shown in Fig. 3, which indicate that the largest enrichment factor was obtained when $0.4-0.6 \mathrm{M}$ sulfuric acid was used. Therefore, $0.5 \mathrm{M}$ sulfuric acid was introduced in the following studies. After mixing with the $\mathrm{S}$ in the donor stream, this corresponding to $0.08 \mathrm{M} \mathrm{H}_{2} \mathrm{SO}_{4}$ that is in accordance with the literature reported optimal results $[19,20]$.

\subsubsection{The $\mathrm{pH}$ and concentration of the acceptor}

Alkaline acceptor should be used to trap these studied weak acidic compounds in the A stream.

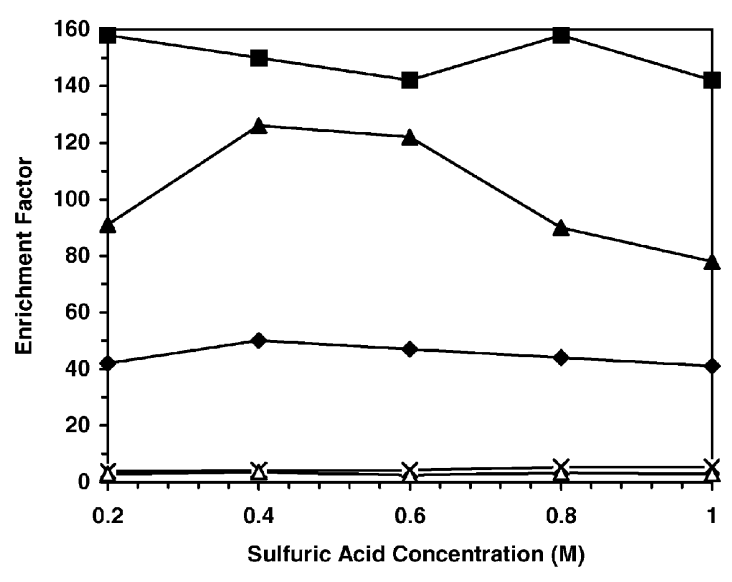

Fig. 3. Effect of sulfuric acid concentration on the enrichment factor. Flow rate: $2 \mathrm{ml} \mathrm{min}^{-1} \mathrm{~S} ; 0.4 \mathrm{ml} \mathrm{min}^{-1}$ of $\mathrm{H}_{2} \mathrm{SO}_{4} ; 0.05 \mathrm{ml} \mathrm{min}^{-1}$ dichloromethane; $0.8 \mathrm{ml} \mathrm{min}^{-1} 12 \mathrm{~g} \mathrm{l}^{-1}$ $\mathrm{Na}_{2} \mathrm{HPO}_{4} \cdot 12 \mathrm{H}_{2} \mathrm{O}(\mathrm{pH}$ 9.0) acceptor; enrichment time: $10 \mathrm{~min}$; analyte concentration: $100 \mu \mathrm{g} 1^{-1}$. The symbol ( $\left.\mathbf{\Delta}\right) \mathrm{MSM} ;(\times)$ BSM; $(\triangle)$ TBM; $(\diamond)$ SMM; ( $)$ DPX-A.

The $\mathrm{pH}$ of acceptor was optimized using Kolthoff buffer solutions. They are $\mathrm{KH}_{2} \mathrm{PO}_{4}-\mathrm{Na}_{2} \mathrm{~B}_{4} \mathrm{O}_{7}$ buffer for $\mathrm{pH} 7.0-9.0, \mathrm{Na}_{2} \mathrm{HPO}_{4}-\mathrm{NaOH}$ buffer for $\mathrm{pH}$ $10.0-12.0$, and $0.1 \mathrm{M} \mathrm{NaOH}$ for $\mathrm{pH}$ 13.0. Results shown in Fig. 4 demonstrated that while the largest enrichment factor was obtained at $\mathrm{pH} 9.0$ for MSM,

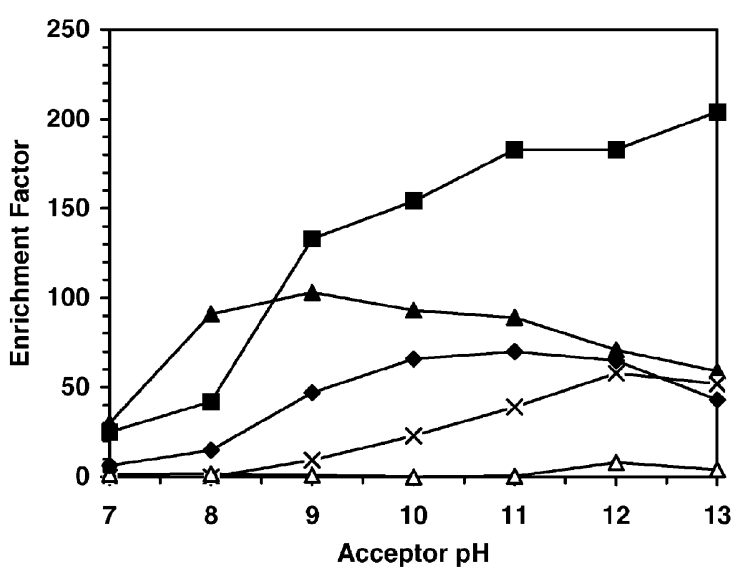

Fig. 4. Effect of buffer $\mathrm{pH}$ on the enrichment factor. Flow rate: $2 \mathrm{ml} \mathrm{min}^{-1} \mathrm{~S}$; $0.4 \mathrm{ml} \mathrm{min}^{-1}$ of $0.5 \mathrm{M} \mathrm{H}_{2} \mathrm{SO}_{4}, 0.05 \mathrm{ml} \mathrm{min}^{-1}$ dichloromethane; $0.8 \mathrm{ml} \mathrm{min}^{-1}$ acceptor; enrichment time: $10 \mathrm{~min}$; analyte concentration: $100 \mu g 1^{-1}$. The symbol $(\mathbf{\Delta}) \mathrm{MSM} ;(\times)$ BSM; $(\triangle)$ TBM; $(\diamond)$ SMM; ( $)$ DPX-A. 


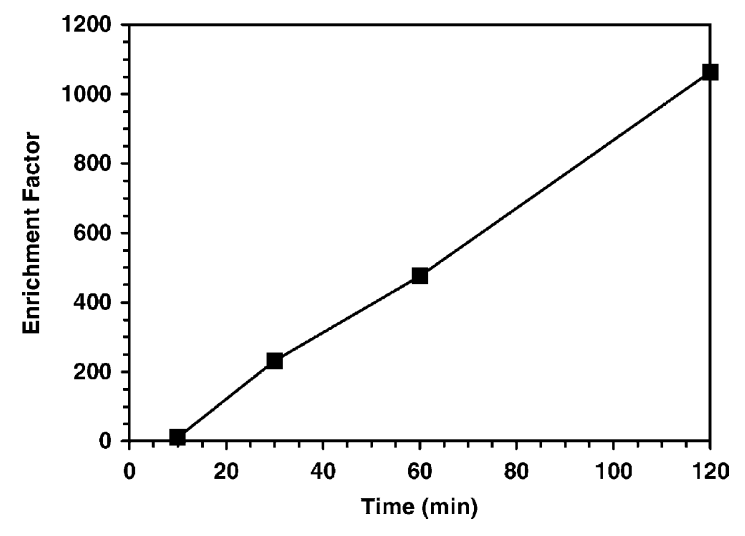

Fig. 5. Effect of enrichment time on the enrichment factor $10 \mu \mathrm{g}^{-1}$ MSM. Flow rate: $2 \mathrm{ml} \mathrm{min}^{-1} \mathrm{MSM} \mathrm{S} ; 0.4 \mathrm{ml} \mathrm{min}^{-1}$ of $0.5 \mathrm{M}$ $\mathrm{H}_{2} \mathrm{SO}_{4}, 0.05 \mathrm{ml} \mathrm{min}^{-1}$ dichloromethane; $0.8 \mathrm{ml} \mathrm{min}^{-1}$ of $0.1 \mathrm{M}$ $\mathrm{Na}_{2} \mathrm{HPO}_{4}-\mathrm{NaOH}(\mathrm{pH} 12.0)$ buffer.

the largest enrichment factors for the other four compounds were obtained at $\mathrm{pH} 11.0-12$. This is in agreement with their $\mathrm{p} K_{\mathrm{a}}$ values, as the $\mathrm{p} K_{\mathrm{a}}$ of MSM is 3.3 while it was in the range of 5-6 for the other four analytes.

As the three kinds of buffer solutions used have different concentrations, it is necessary to investigate the influence of buffer concentration on the enrichment factor. This was done by determining the enrichment factors when the $0.1 \mathrm{M} \mathrm{Na}_{2} \mathrm{HPO}_{4}-\mathrm{NaOH}(\mathrm{pH}$ 12.0) buffer was diluted different folds with water. Results demonstrated that no significant difference presented when different concentration of buffer solution was used. A Kolthoff buffer solution, $0.1 \mathrm{M}$ $\mathrm{Na}_{2} \mathrm{HPO}_{4}-\mathrm{NaOH}$ ( $\mathrm{pH}$ 12.0), was employed as acceptor in the following studies.

\subsubsection{Enrichment time}

For long time enrichment, the $\mathrm{pH}$ of acceptor chamber might changed and thus affect the enrichment efficiency. In this study, the influence of time on enrichment factor was studied by using the enrichment factor of $10 \mu \mathrm{g} 1^{-1}$ MSM as a model. Fig. 5 shows the effect of enrichment time in the range of $10-120 \mathrm{~min}$, which indicates that over 1000 -folds of concentration were obtained when samples were concentrated $120 \mathrm{~min}$.

\subsection{Some characteristics of the system}

To examine the repeatability of the system, $50 \mu \mathrm{g} 1^{-1}$ MSM and TBM were studied. With enrichment time of $20 \mathrm{~min}$ and the repeated time of $5 \mathrm{~min}$, the R.S.D. for MSM and TBM were 5 and $2.9 \%$, respectively.

To examine the carry-over effect of the proposed CFLME system, a water blank was extracted in the same way after $20 \mathrm{~min}$ extraction of individual $50 \mu \mathrm{g} 1^{-1}$ MSM or TBM solution. The carry-over effects, calculated as $P_{\mathrm{b}} /\left(P_{\mathrm{b}}+P_{\mathrm{s}}\right)$ (where $P_{\mathrm{b}}$ and $P_{\mathrm{s}}$ were the peak heights of the blank and the sample extraction, respectively) were all less than $5 \%$.

The linearity of the system was investigated by performing 30 min enrichment of a series solutions containing 1, 10, 50 and $100 \mu \mathrm{g} 1^{-1}$ MSM, respectively. Experiments show that the peak height $(A, \mathrm{mAU})$ and concentration $\left(C, \mu \mathrm{gl}^{-1}\right)$ were related by the regression equation $A=2.443 C+11.15$ with a correlation coefficient of $r=0.9984$. The detection limit, calculated as $3 \sigma$ above the blank value (where $\sigma$ is the S.D. ( $n=5$ ) for a blank solution), was $0.6 \mu \mathrm{g} 1^{-1}$.

In the proposed CFLME procedure, the dichloromethane liquid membrane is continuously renewed thus it is always stable. Experiments demonstrated that there is no significant difference between the enrichment factors of a $10 \mu \mathrm{g} 1^{-1}$ MSM standard solution during 2 months usage of the PTFE membrane. The flowing organic solvent film on the surface of the PTFE membrane of the SLM device prevented the particles and macromolecules in samples from contacting with the PTFE membrane and thus decrease the danger of clog of the micro-pore of the PTFE membrane.

\section{Conclusion}

Combining continuous flow liquid-liquid extraction and SLM, a novel automatic technique was developed for trace-enrichment. As polar organic solvents can be used as liquid membrane, this CFLME technique provided freedom to select liquid membrane. When $10 \mu \mathrm{g} 1^{-1}$ of MSM was pre-concentrated for $120 \mathrm{~min}$, an enrichment factor over 1000 was obtained. Another advantage of this CFLME procedure is the stability of the liquid membrane, which is stable without the danger of the membrane breakthrough, and this 
phenomenon was often occurred in the original SLM procedure. This procedure needs an additional pump to deliver organic phase and the consumption of organic phase, typically controlled at $0.05 \mathrm{ml} \mathrm{min}^{-1}$, is a little bit higher. By using this technique, an automatic CFLME procedure can be easily accomplished, which is indeed a hopeful sample pretreatment platform for various selective detectors. Further studies on the on-line coupling CFLME with HPLC and CE for determination of sulfonylurea herbicides were conducted in this laboratory.

\section{Acknowledgements}

This work was supported by the National Natural Science Foundation of China (20177026 and 29825114) and the Chinese Academy of Sciences.

\section{References}

[1] M.-C. Hennion, in: D. Barcelo (Ed.), Sample Handling and Trace Analysis of Pollutants, Elsevier, Amsterdam, 2000, p. 5 (Chapter 1).

[2] J.Å. Jönsson, L. Mathiasson, Trends Anal. Chem. 18 (1999) 318-324.

[3] G. Audusson, Anal. Chem. 58 (1986) 2714-2723.

[4] J.Å. Jönsson, L. Mathiasson, J. Chromatogr. A 902 (2000) 205-225.

[5] V. Wallace, Anal. Biochem. 20 (1967) 411-418.

[6] N.R. Kuzel, J. Pharm. Sci. 57 (1968) 852-855.

[7] B. Karlberg, S. Thelander, Anal. Chim. Acta 98 (1978) 1-7.

[8] F.H. Berggamin, J.X. Medeiros, B.F. Ries, E.A.G. Zagatto, Anal. Chim. Acta 101 (1978) 9-16.

[9] L. Nord, B. Karlberg, Anal. Chim. Acta 145 (1983) 151-158.
[10] M. Bengtsson, G. Johansson, Anal. Chim. Acta 158 (1984) 147-156.

[11] L. Nord, K. Backstrom, L.-G. Danielsson, F. Ingman, B. Karlberg, Anal. Chim. Acta 194 (1987) 221-233.

[12] C.A. Lucy, F.F. Cantwell, Anal. Chem. 61 (1989) 101-107.

[13] C.A. Lucy, K.K.-C. Yeung, Anal. Chem. 66 (1994) 22202225.

[14] C.A. Lucy, S. Varkey, Anal. Chem. 67 (1995) 3036-3041.

[15] Y. Luo, R. Al-Othman, J. Ruzicka, G.D. Christian, Analyst 121 (1996) 601-606.

[16] J.Å. Jönsson, L. Mathiasson, Trends Anal. Chem. 18 (1999) $325-334$.

[17] J.Å. Jönsson, L. Mathiasson, Trends Anal. Chem. 11 (1992) $106-114$.

[18] J.Å. Jönsson, L. Mathiasson, J. Chromatogr. A 902 (2000) 205-225.

[19] G. Nilve, R. Stebbins, Chromatographia 32 (1991) 269-277.

[20] G. Nilve, M. Knutsson, J.Å. Jönsson, J. Chromatogr. A 688 (1994) 75-82.

[21] J. Trocewicz, J. Chromatogr. A 688 (1996) 121-127.

[22] N. Megersa, J.Å. Jönsson, Analyst 123 (1998) 225-231.

[23] N. Megersa, T. Solomon, J.Å. Jönsson, J. Chromatogr. 830 (1999) 203-210.

[24] G. Nilve, G. Audunsson, J.Å. Jönsson, J. Chromatogr. 471 (1989) 151-160.

[25] M. Knutsson, G. Nilve, L. Mathiasson, J.Å. Jönsson, J. Agric. Food Chem. 40 (1992) 2413-2417.

[26] M. Knutsson, L. Mathiasson, J.Å. Jönsson, Chromatographia 42 (1996) 165-170.

[27] J. Norberg, A. Zander, J.Å. Jönsson, Chromatographia 46 (1997) 483-488.

[28] N.-K. Djane, K. Ndung'u, F. Malcus, G. Johansson, Fresenius J. Anal. Chem. 358 (1997) 822-827.

[29] N. Parthasarathy, M. Pelletier, J. Buffle, Anal. Chim. Acta 350 (1997) 183-195.

[30] E. Thordarson, S. Palmarsdottir, L. Mathiasson, J.Å. Jönsson, Anal. Chem. 68 (1996) 2559-2563.

[31] S. Palmarsdottir, E. Thordarson, L.-E. Edholm, J.Å. Jönsson, L. Mathiasson, Anal. Chem. 69 (1997) 1732-1737.

[32] C.A. Lucy, F.F. Cantwell, Anal. Chem. 61 (1989) 107-114. 